\title{
Trends in environmental tobacco smoke restrictions in the home in Victoria, Australia
}

\author{
Ron Borland, Robyn Mullins, Lisa Trotter, Victoria White
}

\begin{abstract}
Objective-To assess the extent to which smokers and non-smokers in Victoria, Australia attempt to keep their homes smoke free and to determine whether the proportion of people attempting to do so has changed over time.

Methods-Face to face surveys conducted in Victoria each year from 1989 to 1997. Participants-Approximately 2500 randomly selected adults each year.

Main outcome measures-Proportion of respondents who discourage their visitors from smoking; proportion of smokers who always smoke outside their own homes; behaviour of smokers when they are around children. Changes in each of these measures over time.

Results-Reports of visitors being discouraged from smoking rose from $27 \%$ in 1989 to $53 \%$ in 1997 . Smokers who reported always smoking outside the home rose from $20 \%$ in 1995 to $28 \%$ in 1997. Not smoking in the presence of children rose from $14 \%$ in 1989 to $33 \%$ in 1996. Indoor restrictions on smoking were associated with the presence of children in the household and even more strongly with the presence of non-smoking adults. People who worked in places where smoking was totally banned were more likely to ask their visitors not to smoke than those who worked where smoking was allowed. Conclusions-The results indicate a strong move towards homes and towards protecting children from smoke. Efforts to support and facilitate this social change should be further encouraged.

(Tobacco Control 1999;8:266-271)
\end{abstract}

Keywords: children; environmental tobacco smoke; home

Centre for Behavioural Research in Cancer, Anti-Cancer Council of Victoria,

1 Rathdowne Street, Carlton South,

Victoria 3053,

Australia

$\mathrm{R}$ Borland

R Mullins

L Trotter

V White

Correspondence to: Dr Ron Borland.

email: ron@accv.org.au

Received 30 November 1998 Revision received 26 May

1999

Accepted 9 June 1999
Health and Medical Research Council published a report ${ }^{2}$ which concluded that passive smoking increases the risk of some diseases in children and adults, particularly respiratory diseases and disorders. More recently, the United States Environmental Protection Agency has published a report ${ }^{3}$ classifying ETS as an environmental carcinogen.

In Australia, there has been considerable publicity about the health effects of passive smoking. There has also been a great deal of publicity about a series of legal decisions about passive smoking. For example, in 1991, the Australian Federal Court ruled a claim by the Tobacco Institute of Australia (TIA), a lobbying organisation representing tobacco companies, that the statement "there is little evidence and nothing which proves scientifically that cigarette smoking causes disease in non-smokers" was misleading, and that passive smoking causes lung cancer, asthma attacks, and respiratory disease in children. ${ }^{4}$ In 1992, Liesel Scholem became the first Australian to receive a damages payout after a jury decision for disease caused by exposure to environmental tobacco smoke in the workplace. Before this, several payouts had occurred as a result of out of court settlements.

In 1995, a new health warning "Your smoking can harm others" was introduced onto cigarette packs in rotation with five others, drawing more attention to the issue of ETS. ${ }^{5}$

Against this background of medical evidence and legal decisions, a dramatic change in the acceptability of smoking in workplaces and public places has occurred. In 1988, just 17\% of indoor workers in Victoria were protected by a total ban on smoking in the workplace. By 1995 , this had risen to $66 \%$, with only $12 \%$ saying there were no restrictions on smoking in their workplaces. ${ }^{6}$ Many shopping centres, fast food outlets, and entertainment venues (such as theatre foyers) also introduced smoking restrictions, or went completely smoke free over the same period. Domestic air flights became smoke free in 1987, and by 1997 all public transport was smoke free across Australia, and in Victoria and most others states this included taxis. Public acceptance that ETS is harmful is high, and has been high since at least 1987 when it was first assessed. However, it has not changed appreciably since around the late 1980 s to early 1990 s. $^{7}$

This social change in policy has had a major impact on the degree to which people are exposed to ETS in public places. The other location where people may be exposed to ETS is in their homes, and this is likely to be the 
Table 1 Survey sample characteristics compared with census data

\begin{tabular}{|c|c|c|c|c|c|c|}
\hline & \multicolumn{2}{|c|}{$\begin{array}{l}\text { Sample size, } 1991 \text { survey: } \\
2440\end{array}$} & \multirow{2}{*}{$\begin{array}{l}1991 \\
\text { census } \\
\%\end{array}$} & \multicolumn{2}{|c|}{$\begin{array}{l}\text { Sample size, } 1996 \text { survey: } \\
2358\end{array}$} & \multirow{2}{*}{$\begin{array}{l}1996 \\
\text { census } \\
\%\end{array}$} \\
\hline & $\%$ & $95 \% C I$ & & $\%$ & $95 \% C I$ & \\
\hline All men & 46.4 & 44.5 to 48.4 & 48.8 & 47.6 & 45.6 to 49.6 & 48.6 \\
\hline $16-29$ years & 28.8 & 27.0 to 30.6 & 31.1 & 23.6 & 21.9 to 25.3 & 28.5 \\
\hline $30-49$ years & 40.0 & 38.1 to 42.0 & 37.7 & 38.6 & 36.6 to 40.6 & 38.6 \\
\hline $50+$ years & 31.1 & 29.3 to 33.0 & 31.1 & 37.8 & 35.9 to 39.8 & 32.9 \\
\hline
\end{tabular}

CI, confidence interval.

major source of exposure for many children, and also for non-smoking adults who live with smokers.

In 1992, in Victoria, a state in Australia with a population of about four million, a concerted media campaign was run about passive smoking in the home. In that year a television advertisement urged those smokers who felt they were unable to give up at least not to expose their children to smoke. The suggestion was that smoking parents should smoke outside, and that all parents should ban smoking in their homes. The advertising was backed up with the widespread distribution of stickers declaring "This is a smoke-free home." Evaluation of this campaign indicated a strong positive impact among non-smokers, but some evidence of reactive effects among smokers, ${ }^{8}$ although later work indicated that the negative effects were short lived. ${ }^{7}$

In this paper we report on trends in the efforts people in Victoria, Australia, make to keep their homes smoke free and protect children from ETS, and look at some factors which may influence these behavioursspecifically the composition of the household, working in places where smoking is totally banned, and the belief that passive smoking is harmful.

\section{Methods}

For many years, the Centre for Behavioural Research in Cancer (CBRC) has included questions in surveys conducted by a large market research company which interviews a representative sample of Victorians in their own homes. The company conducts an omnibus survey each week, and the CBRC has included questions on smoking in eight to 10 weeks each year, always in the latter part of the year. Since 1989, the surveys have included questions about ETS. The market research company selects clusters of eight households from randomly selected places within specified strata, including rural/urban divisions. Trained interviewers are instructed to make three attempts to contact a selected household before replacing that household, and select a participant according to a selection key which produces accurate cross sections of each sex by age. The sampling design and survey techniques have not changed over the period described here.

These data were taken from Victoria-wide face to face surveys conducted in 1989 ( $\mathrm{n}=$ 2334), $1991(\mathrm{n}=2440), 1992(\mathrm{n}=2355)$, $1994(\mathrm{n}=2485), 1995(\mathrm{n}=2450), 1996(\mathrm{n}=$ 2358), and $1997(n=2365)$. Response rates are available for 1994 onwards, and range from
$33.2 \%$ to $36.8 \%$. The overall average proportions by smoking status across samples were: smokers $25.6 \%$, ex-smokers $27.9 \%$, and never smokers $46.1 \%$ (including $0.4 \%$ who could not say whether or not they smoked). Table 1 presents details of the sex, age, and urban/rural breakdown of the sample in 1991 and 1996 compared with the Victorian census data for those years (the only years for which such data were collected). ${ }^{9}{ }^{10}$ This suggests that the samples slightly underrepresent men and those under 30, and that in 1996 those over 50 were overrepresented. People from Melbourne (the capital city of Victoria) were underrepresented as a proportion of the total population in 1996. In all, however, the samples are a reasonable representation of the Victorian population.

The key questions of interest are:

- Are visitors usually discouraged from smoking in this home or not? (asked in 1989, 1991, 1992, 1994, 1995, 1996, and 1997).

- Do you or any other regular smokers living in this household: always smoke inside; usually smoke inside; sometimes smoke inside and sometimes smoke outside; usually smoke outside or always smoke outside? (1995, 1996, 1997).

- When you're with children do you smoke more than normally, less than normally, about the same amount, or not at all? (1989, 1992, 1994, 1996).

In some years respondents were also asked about their beliefs about whether passive smoking is harmful to non-smokers (1989, 1991, 1995, 1996, 1997) and indoor workers were asked what restrictions on smoking were in place where they worked (in all years except 1996).

Respondents were asked how many people aged 16 or over and how many children aged less than 16 lived in the household. They were also asked how many people in the household smoked. This was used to divide the respondents into three categories of household composition: those from households where the adult smoked or all the adults smoked; those from households where there were a mix of smoking and non-smoking adults; and those where no adult in the house smoked. Each of these categories of household composition was then divided into those with and without children under 16 .

\section{STATISTICAL ANALYSES}

For most questions we present the point prevalence estimates and their $95 \%$ confidence intervals (CI) for the year the question was asked, by household composition and by whether children were present or not. Multiple logistic regression analyses were used to examine the significance of changes over the survey years and the impact of household composition and the presence of children. In these models, the predicted variable was recoded into a dichotomous variable and the model predicted the favourable behaviour (that is, always asking visitors to smoke outside, smokers always going outside to smoke at home, and smokers either not smoking or smoking less when 
around children). Year was entered as a categorical variable with the first year the question was asked presented as the base year. Household composition was a three level variable where a household where all adults smoked was the base level and the presence of children was dichotomous, with no children under 16 being the base level. Interaction terms were included in the model to examine whether the impact of household composition and the presence of children was consistent across the year. Logistic regression was also used to examine the impact of working where smoking was banned on respondents asking visitors to smoke outside and on smokers going outside to smoke. In these models, occupational status and household composition were controlled for. All analyses were undertaken using the statistical package SPSS. A significance level of 0.05 was adopted.

\section{Results}

VISITORS SMOKING OUTSIDE

The proportion of respondents who reported requesting that visitors smoke outside increased across the study period. In 1989, only $27 \% \quad(95 \% \quad$ CI 24.8 to 28.4$)$ of respondents indicated that they discouraged visitors from smoking, but by 1997 this proportion had nearly doubled to 53\% (95\% CI $51 \%$ to $55 \%$ ). Table 2 presents the data for respondents discouraging visitors from smoking in the house by the smoking status of the adults in the household and by the presence of children in the household for all years the data were collected.
Across all years, respondents from nonsmoking households were more likely to request that their visitors smoke outside than those from either mixed households or smoking households. However, there was a significant interaction between year and household composition $\left(\chi^{2}=41.41, \mathrm{df}=12, \mathrm{p}<0.001\right)$, indicating that this difference reduced over the nine year period as more respondents from smoking households also asked visitors to smoke outside the home. In 1989, non-smoking households were nearly 22 times more likely to ask visitors to smoke outside than were smoking households (odds ratio (OR) 21.92; 95\% CI 11.1 to 43.5) but by 1997 non-smoking households were only six times more likely to ask visitors to smoke outside (OR $6.4 ; 95 \%$ CI 4.8 to 8.5 ). Similarly the difference between mixed households and smoking households also lessened. In 1989, the OR for mixed households was 7.6 (95\% CI 3.7 to 15.4 ) while in 1997 the OR was 3.1 (95\% CI 2.3 to 4.2 )

Adding children to a household had an impact on the likelihood of asking visitors to smoke outside on top of the effect of smoking status of the adults in the household in later years, but not initially. In 1989 and 1991 there was no difference in the proportion of non-smoking, mixed, or smoking households with or without children asking visitors to smoke outside $\left(1989, \chi^{2}=0.72, \mathrm{df}=1, \mathrm{p}>0.40 ; 1991\right.$, $\left.\chi^{2}=0.78, \mathrm{df}=1, \mathrm{p}>0.38\right)$. However, from 1992 onwards, households with children were more likely to ask visitors to smoke outside compared with households with no children

Table 2 Visitors discouraged from smoking (1989-1997) by household composition

\begin{tabular}{|c|c|c|c|c|c|c|c|c|c|}
\hline & \multicolumn{9}{|c|}{ No smoker in house } \\
\hline & \multicolumn{3}{|c|}{ Children } & \multicolumn{3}{|c|}{ No children } & \multicolumn{3}{|l|}{ Total } \\
\hline & $N$ & $\%$ & $95 \% C I$ & $N$ & $\%$ & $95 \% C I$ & $N$ & $\%$ & $95 \% C I$ \\
\hline 1989 & 501 & 35.9 & 31.7 to 40.1 & 832 & 38.2 & 34.9 to 41.5 & 1333 & 37.4 & 34.8 to 40.0 \\
\hline 1991 & 532 & 47.4 & 43.1 to 51.6 & 925 & 43.9 & 40.7 to 47.1 & 1457 & 45.2 & 42.6 to 47.7 \\
\hline 1992 & 445 & 61.8 & 57.3 to 66.3 & 943 & 50.4 & 47.2 to 53.6 & 1388 & 54.0 & 51.4 to 56.7 \\
\hline 1994 & 520 & 67.9 & 63.9 to 71.9 & 1039 & 55.9 & 52.9 to 58.9 & 1559 & 59.9 & 57.5 to 62.3 \\
\hline 1995 & 479 & 68.9 & 64.7 to 73.0 & 1047 & 56.4 & 53.3 to 59.4 & 1526 & 60.3 & 57.8 to 62.7 \\
\hline 1996 & 455 & 68.8 & 64.5 to 73.0 & 1069 & 55.3 & 52.3 to 58.3 & 1524 & 59.3 & 56.9 to 61.8 \\
\hline \multirow[t]{4}{*}{1997} & 449 & 69.7 & 65.5 to 74.0 & 1012 & 60.5 & 57.5 to 63.5 & 1461 & 63.3 & 60.8 to 65.8 \\
\hline & \multicolumn{9}{|c|}{ Mixed smoker/non-smoker household } \\
\hline & \multicolumn{3}{|c|}{ Children } & \multicolumn{3}{|c|}{ No children } & \multicolumn{3}{|l|}{ Total } \\
\hline & $N$ & $\%$ & $95 \% C I$ & $N$ & $\%$ & $95 \% C I$ & $N$ & $\%$ & $95 \% C I$ \\
\hline 1989 & 290 & 16.9 & 12.6 to 21.2 & 371 & 17.3 & 13.4 to 21.1 & 661 & 17.1 & 14.2 to 20.0 \\
\hline 1991 & 269 & 19.0 & 14.3 to 23.6 & 380 & 22.4 & 18.2 to 26.6 & 649 & 21.0 & 17.8 to 24.1 \\
\hline 1992 & 273 & 28.9 & 23.6 to 34.3 & 387 & 23.5 & 19.3 to 27.7 & 660 & 25.8 & 22.4 to 29.1 \\
\hline 1994 & 235 & 38.3 & 32.1 to 44.5 & 362 & 32.9 & 28.0 to 37.7 & 597 & 35.0 & 31.2 to 38.8 \\
\hline 1995 & 242 & 42.6 & 36.3 to 48.8 & 345 & 28.1 & 23.4 to 32.9 & 587 & 34.1 & 30.2 to 37.9 \\
\hline 1996 & 198 & 47.0 & 40.0 to 53.9 & 325 & 36.6 & 31.4 to 41.9 & 523 & 40.5 & 36.3 to 44.7 \\
\hline \multirow[t]{4}{*}{1997} & 211 & 52.6 & 45.9 to 59.3 & 354 & 41.2 & 36.1 to 46.4 & 565 & 45.5 & 41.4 to 49.6 \\
\hline & \multicolumn{9}{|c|}{ All adult smokers } \\
\hline & \multicolumn{3}{|c|}{ Children } & \multicolumn{3}{|c|}{ No children } & \multicolumn{3}{|l|}{ Total } \\
\hline & $N$ & $\%$ & $95 \% C I$ & $N$ & $\%$ & $95 \% C I$ & $N$ & $\%$ & $95 \% C I$ \\
\hline 1989 & 138 & 2.2 & -0.03 to 4.6 & 202 & 3.0 & 0.6 to 5.3 & 340 & 2.6 & 0.9 to 4.4 \\
\hline 1991 & 150 & 8.7 & 4.2 to 13.2 & 184 & 4.9 & 1.8 to 8.0 & 334 & 6.6 & 3.9 to 9.2 \\
\hline 1992 & 110 & 11.8 & 5.8 to 17.9 & 197 & 5.6 & 2.4 to 8.8 & 307 & 7.8 & 4.8 to 10.8 \\
\hline 1994 & 139 & 21.6 & 14.7 to 28.4 & 190 & 5.8 & 2.5 to 9.1 & 329 & 12.5 & 8.9 to 16.0 \\
\hline 1995 & 131 & 26.0 & 18.4 to 33.5 & 206 & 8.3 & 4.5 to 12.0 & 337 & 15.1 & 11.3 to 19.0 \\
\hline 1996 & 129 & 26.4 & 18.8 to 34.0 & 182 & 14.3 & 9.2 to 19.4 & 311 & 19.3 & 14.9 to 23.7 \\
\hline 1997 & 125 & 32.0 & 23.8 to 40.2 & 214 & 15.0 & 10.2 to 19.7 & 339 & 21.2 & 16.9 to 25.6 \\
\hline
\end{tabular}

CI, confidence interval. 
(1992, OR $=1.5,95 \%$ CI 1.3 to $1.9 ; 1994$, OR $=1.7,95 \%$ CI 1.4 to $2.0 ; 1995$, OR $1.9,95 \%$ CI 1.6 to $2.3 ; 1996, \mathrm{OR}=1.7,95 \%$ CI 1.4 to 2.1 ; $1997, \mathrm{OR}=1.6,95 \%$ CI 1.4 to 2.0 ).

Looking only at data from 1996, the belief that passive smoking is harmful to the health of non-smokers was related to asking visitors to smoke outside after adjusting for adult smoking status and presence of children. Respondents who held this belief were 3.2 times more likely to ask their visitors to smoke outside.

Data from 1997 indicate that respondents from workplaces where smoking was banned completely were more likely to discourage their visitors from smoking in their homes than were those from workplaces with partial or no smoking bans (OR $=1.8,95 \%$ CI 1.4 to 2.3 ). This effect remained significant after controlling for respondents' occupational status and household composition (OR $=1.5$, 95\% CI 1.2 to 2.0 ).

BEHAVIOUR OF SMOKERS IN THEIR OWN HOMES

Table 3 presents the data on where smokers smoked at home for 1995, 1996, and 1997. Over this time, the proportion of smokers who usually smoked outside increased from $20.0 \%$ (95\% CI 17.4 to 22.6 ) to $28.0 \%$ (95\% CI 25.0 to 30.9 ).

Logistic regression was used to examine the impact of the household composition and the presence of children on where respondents smoked (table 4$)$. There was a significant effect of year $\left(\chi^{2}=16.2, p<0.001\right)$, indicating that the proportion of respondents who reported that they always smoked outside increased between 1995 and 1997. Combining the data for all years, smokers in mixed households were more likely to always smoke outside than smokers in an all smoker household (OR $=4.7,95 \%$ CI 3.7 to 6.0 ). There was no interaction of year and household composition, suggesting that this difference was consistent across all three survey years. After adjusting for household composition and year, the presence of children made a significant impact on the likelihood of always smoking outside. Smokers in households with children were 1.6 times more likely to always smoke outside than those in households with no children $(\mathrm{OR}=1.6,95 \%$ CI 1.3 to 2.0$)$. The interaction between year and presence of children was not significant. The interaction between household composition and presence of children was just significant $\left(\chi^{2}=3.9, \mathrm{df}=1\right.$, $\mathrm{p}=0.05)$ indicating that having children in the household was more important in smoking households than mixed households in encouraging smoking outside.

After the presence of non-smoking adults and children in the household had been taken into account, an analysis of data from 1996 indicated that the belief that non-smokers health can be damaged by passive smoking had an impact on the probability of smokers going outside to smoke (OR $=1.9,95 \%$ CI 1.2 to 2.9 ).

Data from 1995 and 1997 were used to investigate whether workplace smoking bans had an impact on where smokers smoke at home. After controlling for year, respondent occupation, and household composition, workplace smoking bans did not have a significant impact on whether a smoker smoked inside or outside at home.

Overall in 1997, in $22 \%$ of homes where at least one smoker lived, the smoker(s) always

Table 3 Household smoking habits by year

\begin{tabular}{|c|c|c|c|c|c|c|}
\hline & \multicolumn{2}{|c|}{$1995, N=907$} & \multicolumn{2}{|c|}{$1996, N=809$} & \multicolumn{2}{|c|}{$1997, N=880$} \\
\hline & $\%$ & $95 \% C I$ & $\%$ & $95 \% C I$ & $\%$ & $95 \% C I$ \\
\hline Always/usually inside & 39.0 & 35.9 to 42.2 & 28.4 & 25.3 to 31.5 & 24.7 & 21.8 to 27.5 \\
\hline Sometimes in, sometimes out & 30.0 & 27.0 to 33.0 & 34.4 & 31.1 to 37.6 & 33.4 & 30.3 to 36.5 \\
\hline Usually outside & 11.0 & 0.9 to 13.1 & 13.7 & 11.3 to 16.1 & 14.0 & 11.7 to 16.3 \\
\hline Always outside & 20.0 & 17.4 to 22.6 & 23.5 & 20.6 to 26.4 & 28.0 & 25.0 to 30.9 \\
\hline
\end{tabular}

CI, confidence interval.

Table 4 Proportion of smokers who always smoke outside at home by household composition

\begin{tabular}{|c|c|c|c|c|c|c|c|c|c|}
\hline & \multicolumn{3}{|l|}{1995} & \multicolumn{3}{|l|}{1996} & \multicolumn{3}{|c|}{1997} \\
\hline & $N$ & $\%$ & $95 \% C I$ & $N$ & $\%$ & $95 \% C I$ & $N$ & $\%$ & $95 \% C I$ \\
\hline \multicolumn{10}{|l|}{ Smoker(s) } \\
\hline Children & 129 & 9.3 & 4.3 to 14.3 & 128 & 14.1 & 8.0 to 20.1 & 118 & 17.8 & 10.9 to 24.7 \\
\hline No children & 201 & 4.5 & 1.6 to 7.3 & 181 & 8.3 & 4.3 to 12.3 & 204 & 5.9 & 2.7 to 9.1 \\
\hline \multicolumn{10}{|l|}{ Mixed } \\
\hline Children & 242 & 31.0 & 25.2 to 36.8 & 198 & 36.9 & 30.1 to 43.6 & 211 & 43.1 & 36.4 to 49.8 \\
\hline No children & 345 & 24.6 & 20.1 to 29.2 & 325 & 25.8 & 21.1 to 30.6 & 354 & 34.5 & 29.5 to 39.4 \\
\hline
\end{tabular}

CI, confidence interval.

Table 5 Smoking in the presence of children

\begin{tabular}{|c|c|c|c|c|c|c|c|c|}
\hline & \multicolumn{2}{|c|}{$1989, N=654$} & \multicolumn{2}{|c|}{$1992, N=606$} & \multicolumn{2}{|c|}{$1994, N=615$} & \multicolumn{2}{|c|}{$1996, N=574$} \\
\hline & $\%$ & $95 \% C I$ & $\%$ & $95 \% C I$ & $\%$ & $95 \% C I$ & $\%$ & $95 \% C I$ \\
\hline Smoke more & 1.2 & 0.4 to 2.1 & 1.7 & 0.6 to 2.7 & 0.8 & 0.1 to 1.5 & 1.1 & 0.2 to \\
\hline No effect & 30.7 & 27.2 to 34.3 & 21.9 & 18.7 to 25.2 & 22 & 18.5 to 25.1 & 19.1 & 15.9 to 22.4 \\
\hline Smoke less & 50.0 & 46.2 to 53.8 & 50.7 & 18.7 to 25.2 & 44.5 & 40.1 to 48.8 & 44.0 & 40.0 to 48.1 \\
\hline Don't smoke at all & 13.6 & 11.0 to 16.2 & 23.1 & 19.7 to 26.5 & 29.1 & 25.5 to 32.7 & 32.6 & 28.8 to 36.5 \\
\hline Can't say & 4.4 & 2.9 to 6.0 & 2.6 & 1.4 to 3.9 & 3.4 & 2.0 to 4.8 & 3.2 & 1.7 to 4.6 \\
\hline
\end{tabular}

CI, confidence interval. 
smoked outside and visitors were discouraged from smoking, indicating a consistent attempt to maintain a smoke-free home.

SMOKING IN THE PRESENCE OF CHILDREN

Table 5 shows how the presence of children influenced the amount respondents smoked for each year the question was asked. From 1989 to 1996 , the number of smokers who said they did not change their smoking consumption when they were with children fell from $31 \%$ to $19 \%$ and the number of smokers who said they do not light up at all when with children increased from $14 \%$ to $33 \%$. We combined the "smoke less" and "don't smoke at all" responses and examined the changes in the proportions of respondents who gave these responses over the years. There was a significant effect of year $\left(\chi^{2}=30.2, \mathrm{df}=3\right.$, $\mathrm{p}<0.001)$ and odds ratios, indicated that compared with 1989 more smokers in 1992 $(\mathrm{OR}=1.6,95 \%$ CI 1.3 to 2.1$), 1994(\mathrm{OR}=$ $1.6,95 \%$ CI 1.3 to 2.1 ), and 1996 (OR $=1.9$, $95 \%$ CI 1.5 to 2.4 ) said they smoked less or not at all when they were with children. We explored whether the effect of year was caused by the increase between 1989 and 1992 by rerunning the analysis for the data from 1992, 1994, and 1996. The effect of year was not significant for this analysis, indicating that there was no change in the proportion of smokers who smoked less or not at all when with children between 1992 and 1996.

Having children under 16 living in the house made it less likely that smokers would stop smoking altogether when children were around $(\mathrm{OR}=0.65,95 \% \mathrm{CI} 0.54$ to 0.78$)$ and this was consistent across all years.

\section{Discussion}

The results indicate a clear and continuing trend towards reduction of ETS exposure around the home on all three indices reported here. This is extremely reassuring and suggests that more progress is likely to be made without the need for intensive interventions. The move to smoke-free homes can be thought of as part of a movement that is promoting this social innovation through the community. ${ }^{11}$

The belief that ETS is harmful to non-smokers has an impact on people choosing to make their homes smoke free, but as most of the change in behaviour occurred after belief in the harm of ETS reached a plateau, this is not a complete explanation. The strong moves towards making smoking less socially acceptable, including restrictions on when and where people can smoke in public and at work, are likely to have contributed.

The data indicate that people who work in places where smoking is banned are more likely to ask their visitors not to smoke. Whether this is because of greater awareness of the risks of passive smoking or the modelling of appropriate behaviour is unclear, but it seems plausible that the experience of smoke-free environments has led to increased self regulation in the home by smokers. However, the failure to find a similar effect for smokers going outside to smoke at home suggests that the effect, if real, is not strong. Broad social change (at the workplace and in public places in general) has probably also influenced the extent to which non-smokers will tolerate exposure to ETS, and their influence is clearly important.

The data show far fewer restrictions in households where all the adults smoke, even when there are also children living there. This remains a cause for concern, as protection of children must be a priority.

It is notable that it was not until 1992, just after an advertising campaign on protecting children from ETS was conducted in Victoria, that the presence of children in the household had impact on visitors being asked to smoke outside. The increase in smoking less, or not smoking at all, around children also occurred between 1989 and 1992. This is evidence of a clear beneficial effect of the advertising campaign.

It is also notable that smokers who have children in the house are more likely to smoke outside, but less likely to stop smoking entirely when children are around. This suggests that people who are frequently with children make less dramatic changes to their behaviour in response to the presence of children than those who are with children only occasionally. The behavioural changes that would be required if they were to protect their children completely from ETS are far greater than the changes required for those who are only in contact with children occasionally.

The study is limited by the relatively poor response rates, which mean that we cannot have confidence in the absolute levels of behaviour reported. The self report methodology contributes to uncertainty as to what respondents really mean, and leaves open the possibility there may be some social desirability bias. The similar response rates across years, however, make it probable that the magnitude of change reported is real. There can be no doubt that major social change is happening, but it would be extremely useful to validate these measures to help provide a clearer picture of the actual nature and extent of not smoking in homes and around children.

The rapid social change reported here contrasts with the mixed effects of focused interventions. Low level interventions do not appear to have had any clear effects, while intense interventions have some effect. ${ }^{12-16}$ It is notable that further follow up of one of these studies found marked changes in the control condition and sustained change in the intervention condition. ${ }^{17}$ This, and our data, suggest that changing social conditions are having quite a strong impact on people. If social conditions continue to change, it is likely that there will be an ongoing increase in the proportion of households imposing restrictions on smoking, which will result in non-smokers (including children) being protected from exposure to ETS wherever they may be.

There are limited data to compare the situation in Australia with that in other countries. In the United States in 1996, it was found that in homes with at least one adult smoker and one 
child, smoking was permitted in at least part of the house in between $70.6 \%$ and $95.6 \%$ of homes. ${ }^{18}$ Biener et al found that in Massachusetts in 1993, 25\% of adolescents living with smokers reported smoking bans and $23 \%$ reported that visitors were not allowed to smoke. ${ }^{19}$ In 1995 , a Scandinavian study of parents of three year olds found that in households with at least one smoker, $30 \%$ did not appear to be exposing the children to any ETS at home. $^{20}$ Although the two latter studies represent specific subsets of the population, they still suggest that in some countries at least, movement towards smoke-free homes is progressing at a broadly similar rate to that in Australia. ${ }^{21}$ However, without data it would be inappropriate to generalise that similar trends were occurring in other countries, especially those with quite different sociocultural profiles.

The results indicate that much can be achieved in ETS control through working at a population level. The marked change that has occurred at a structural level and without intensive intervention suggests that the circumstances in which intensive interventions are necessary may be limited. A continuation of the efforts to make ETS exposure socially unacceptable are well justified and should continue. Public education and programmes to promote smoke-free public places need to ensure that their messages implicitly or explicitly communicate the importance of protecting others from exposure in the home. The results also indicate that a media campaign targeted at encouraging people to protect children from ETS, particularly in their own homes, can be effective. Evidence that an increasing number of people, including smokers, are declaring their homes smoke free needs to be promoted, so that those who have not yet made the move are aware that smoking in the home is becoming unacceptable. This should hasten the transition to a society where non-smokers can expect not to be exposed to ETS.
1 US Department of Health and Human Services. The health consequences of involuntary smoking: a report of the Surgeon General, 1986. Rockville, Maryland: Public Health Service, Centers for Disease Control, 1986. [DHHS Publication No (CDC) 87-8387.]

2 National Health and Medical Research Council. Effects of passive smoking on health. Canberra: Australian Government Publishing Service, 1986.

3 US Environmental Protection Agency. Respiratory effects of passive smoking: lung cancer and other disorders. Washington DC: Office of Research and Development, 1992.

4 Everingham R, Woodward S, eds. Tobacco litigation: the case against passive smoking. Sydney: Legal Books, 1991.

5 Borland R, Hill D. The path to Australia's tobacco health warnings. Addiction 1997;92:1151-7.

6 Borland R, Morand M, Mullins R. Prevalence of workplace smoking bans in Victoria. Aust $N Z \mathcal{F}$ Public Health 1997;21:694-8

7 Mullins R, Morand M. Environmental tobacco smoke: public opinion and behaviour. In Mullins R, ed. Quit evaluation studies No 8: 1994-1996. Carlton South Victorian Smoking and Health Program, 1996.

8 Mullins R, Scollo M, Borland R. Evaluation of a campaign on the effects of passive smoking on children. In Mullins R, ed. Quit evaluation studies No 7: 1992-1993. Carlton Routh: Victorian Smoking and Health Program, 1995.

9 Australian Bureau of Statistics. Census characteristics of Australian Bureau of Statistics. Census characteristics of
Australia: 1991 Census of Population and Housing. Canberra, ABS, 1991. Catalogue No 2710.0 .

10 Australian Bureau of Statistics. Social and Housing characteristics for Statistical Local Areas. Canberra, ABS, 1996. Catalogue No 2015.2.

11 Rogers EM. Diffusion of innovations, 4 th ed. New York: Free Press, 1995.

12 Woodward A, Owen N, Grgurinovich N, et al. Trial of an intervention to reduce passive smoking in infancy. Pediatr Pulmonol 1987;3:173-8.

13 Chilmonczyk BA, Palomaki EG, Knight GJ, et al. An unsuccessful cotine-assisted intervention strategy to reduce environment tobacco smoke exposure during infancy. $\mathrm{Am}$ 7 Dis Child 1992;146:357-60.

14 Eriksen W, Sørum K, Bruusgaard D. Effects of information on smoking behaviour in families with preschool children. Acta Paediatr 1996;85:209-12.

15 Greenberg RA, Strecher VJ, Bauman KE, et al. Evaluation of a home-based intervention program to reduce infant passive smoking and lower respiratory illness. F Behav Med 1994;17:273-90.

16 Hovell MF, Meltzer SB, Zakarian JM, et al. Reduction of environmental tobacco smoke exposure among asthmatic environmental tobacco smoke exposure among as
children: a controlled trial. Chest 1994;106:440-6.

17 Wahlgren DR, Hovell MF, Meltzer SB, et al. Reduction of environmental tobacco smoke exposure in asthmatic children: a 2-year follow-up. Chest 1997;111:81-8.

18 US Centers of Disease Control and Prevention. MMWR 1997;46:1038-43. http://www.cdc.gov/epo/mmwr/preview/ mmwrhtml/00049780.htm

19 Biener L, Cullen D, Di ZX, et al. Household smoking restrictions and adolescents' exposure to environmental tobacco smoke. Prev Med 1997;26:358-63.

20 Lund KE, Skrondal A, Vertio H, et al. To what extent do parents strive to protect their children from environmental parents strive to protect their children from environmental tobacco smoke in the Nordic countries?
based study. Tobacco Control 1998;7:56-60.

21 Ashley MJ, Ferrence R. Reducing children's exposure to environmental tobacco smoke in homes: issues and strategies. Tobacco Control 1998;7:61-5. 